\title{
INTEGRATED SURVEYING FOR THE ARCHAEOLOGICAL DOCUMENTATION OF A NEOLITHIC SITE
}

\author{
Domenica COSTANTINO', Maria Giuseppa ANGELINI', Valerio BAIOCCHI ${ }^{2}$
}

DOI: 10.21163/GT_2016.112.04

\begin{abstract}
:
It has been tested the applicability of integrated surveys (remote sensing, digital photogrammetry and terrestrial laser scanning (TLS)) in order to verify, through gradual and successive steps, how geomatic techniques can get 3D results with metric value combined with a quality content for an archaeological site. In particular, the data have been collected during the excavation campaign of Neolithic archaeological site in Taranto. The possibilities to scan articulated forms, in the presence of curve, concavity and convexity, and jutting parts rotate, characterized by alterations, through the acquisition of a dense points cloud makes the technique TLS needed in archaeology. Through the photogrammetric technique the laser data has been integrated concerning some details found on the site for which it has been required a higher degree of detail. The photogrammetric data has been acquired with the calibrated camera. The processing of the acquired data and their integration has been made possible to study an important archeological site, in its totality, from small scale (general site framework) to large scale (3D model with a high degree of detail) and to structure a multi-temporal database for simplified data management.
\end{abstract}

Key-words: Topographic and cadastral databases, Laser scanning, Photogrammetry, Remote sensing

\section{INTRODUCTION}

\subsection{Historical Introduction}

The Neolithic Era ("New Stone Age") represents one of the most important periods in the history of human civilization because it saw the beginning and evolution of innovative processes in the exploitation of environmental resources. Apulia is one of the most important regions for prehistory in Italy, both for the abundance of remains found and for their comprehensive chronological arrangement. It is in fact considered an area of reference for Europe as a whole due to the importance of the various sites and the palaeo-climatic data one can deduce from their successive strata, as well as the exceptional nature of a number of human fossils found, pertaining to the entire prehistoric chronological arc. The finding of so many prehistoric sites in Apulia can be explained by the environmental context, in which the intrinsic fertility of the soil facilitated the possibility of working it with the limited selection of tools available and water sources were easily available. The areas around "Mar Piccolo" immediately to the North West of the present city of Taranto and all along the southeast coast of the province were those most concerned. The nexus of inhabitation is particularly dense in and around the area that would be subsequently occupied by the city of Taranto. In the zones

1 DICATECh-Politecnico di Bari, 70125 Bari, Italy. domenica.costantino@poliba.it, mariagiuseppa.angelini@poliba.it

2 DICEA - Facoltà di Ingegneria - Sapienza Università di Roma, via Eudossiana, 18 - 00184 Roma (Italy); valerio.baiocchi@uniromal.it 
further inland the Neolithic Revolution probably arrived later and was more sparsely distributed, located especially in the flat karst terraces marked by furrows produced by erosion (blades or ravines), above all in the territories of Grottaglie, San Marzano and the clay hills around the plain of Levrano.

\subsection{Historical to the work}

Ever more frequently we see the necessity of combining the new methodologies of research with the instruments designed to support and increase the knowledge of the cultural patrimony (archaeological, architectural and monumental), with the goal of sustainable guardianship to preserve it and hand it down to future generations.

For this reason in fact UNESCO gives ever more attention to the accurate digitalised metrical documentation of archaeological sites (Dominici et al, 2013; Brigante \& Radicioni, 2014) urban historic centres (Baiocchi et al, 2012; Baiocchi, Dominici \& Mormile, 2013), and archaeological finds. The result is that the idea that knowledge of a given element is not limited to its artistic history but also to its geographical and geometric characteristics.

An important contribution is furnished by the research in the field of Geomatic conducted nation-wide on various scales that allows for example as a function of the process the production of thematic archaeological maps in a digital format, capable of being inserted in geographic information systems (GIS) (Guaitoli, 2000).

For this reason, on the archaeological site from the Neolithic Era located in the province of Taranto called Masseria Cesario, surveys using methodologies of integrated surveying have been carried out using traditional topographic technique, satellite-based GNSS, photogrammetry, laser scanning and elaborations of images obtained using remote sensors.

The integration of the surveying techniques facilitated and supported the work of the archaeologists during all phases of their research and investigation.

\section{THE MASSERIA CESAREO ARCHAEOLOGICAL SITE}

One of the largest Neolithic settlements, named Masseria Cesareo, came to light during construction work in 2003 in relation to the new Naval arsenal and the roadways connected to its service. The site, consisting of a necropolis, is located in the southern periphery of the city of Taranto, along the S.P. 99 roadway near the intersection with the S.P. 101, in Chiapparo locality (Fig. 1).

The necropolis, which dates from the period between the fifth and fourth millennia B.C.E. (Fig. 2), presents archaeological remains testifying to the characteristic religious practices of that period. Numerous human remains were found that document the ritual burial practices, as well as broken pieces of tableware (Coppola, 1988).

The ritual burial entailed the bodies being arranged in a crouched foetal position, and, notably, in artificial niches closed with a double slab of stone, as evidenced in the find of a child and an adult buried next to each other (Gambassini, 1999; Cremonesi, 1979; Corrado \& Ingravallo, 1988). The ceramic elements found have been studied in order to obtain information as to the primary material used, the various stages of workmanship and production, their usage, and, finally, their relationship to the period of burial. The first remains of ceramic objects in the oldest Neolithic communities pertain to manufactures in paste dating to 8000 years ago. In particular, the ceramic samples found are quite heterogeneous in comparison with other archaeological sites in the Taranto area, and for this reason it has been hypothesised that ceramics for domestic use were produced with clay from the subAppennine clays from the area of Bradano (Fedele, 1972; Del Monaco, 1993). 


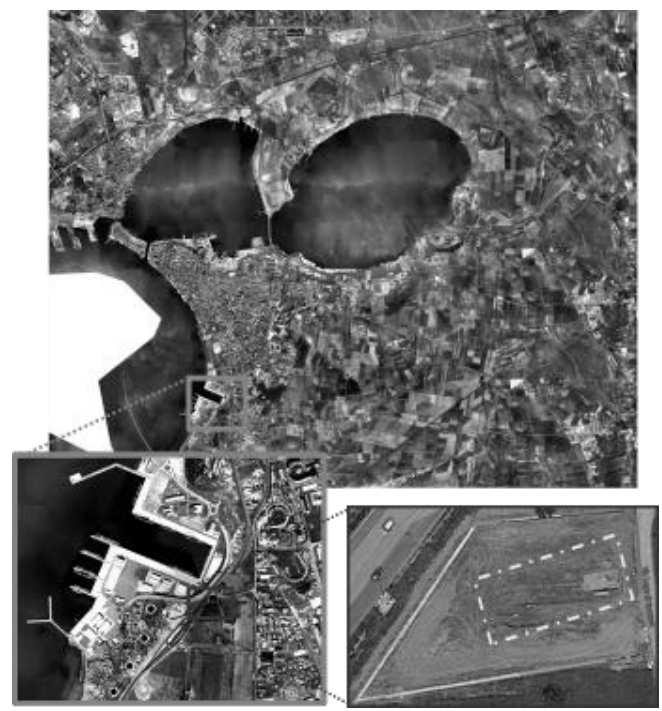

Fig. 1 Position of the site in the area of Taranto
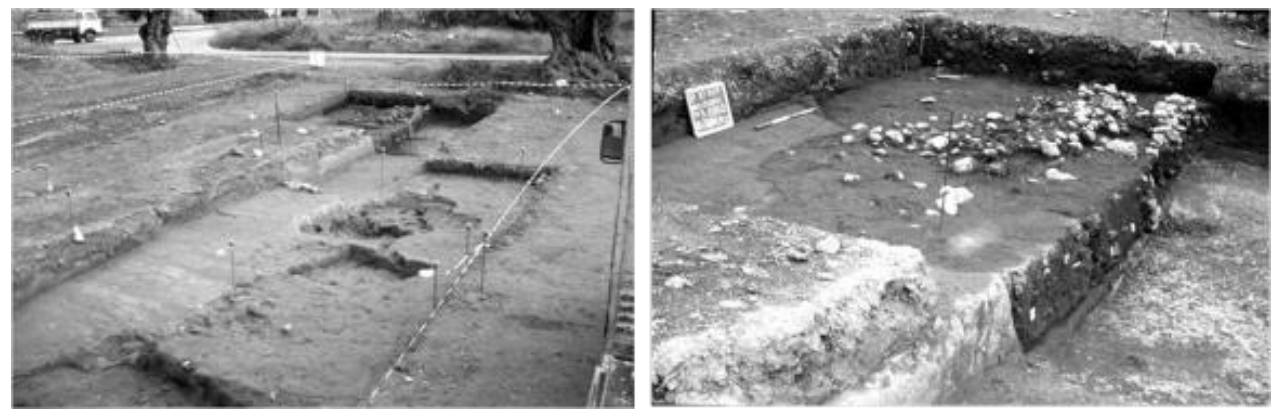

Fig. 2 The Masseria Cesareo archaeological site

The news of the discovery of Neolithic human remains, usually quite rare (as the palaeomedical expert Gaspare Baggieri in the Anthropology department of the Ministry of the Cultural Patrimony has declared), caused a great deal of interest on the part of experts in the Cultural Ministry and archaeologists. The importance of these finds was such that the site was placed under the protection of the Taranto Soprintendenza dei Beni Culturali, giving rise to a series of excavation campaigns that lasted until 2007-2008, involving six excavation trenches.

\section{THE 3D SURVEY}

\subsection{Topographical survey}

The tracing of a topographical support network is a basic operation that allows for the definition of a local reference system on the basis of which it is possible to align the laser scans. Using the framework provided by the topographical network it is also possible to georeference the excavation in the national reference system. 
The choice of topographical stations and the placement of the points for positioning the natural and artificial targets was conditioned by the presence of various gray zones caused by the sunken and indented conformation of the area. The solution of linking the principal polygon defining the external vertices of the area, which was closed and therefore compensable (Fig. 3), to the internal points of the excavation area allowed for tightening the geometry of the network, thus limiting any eventual spread of errors (Fig. 4).

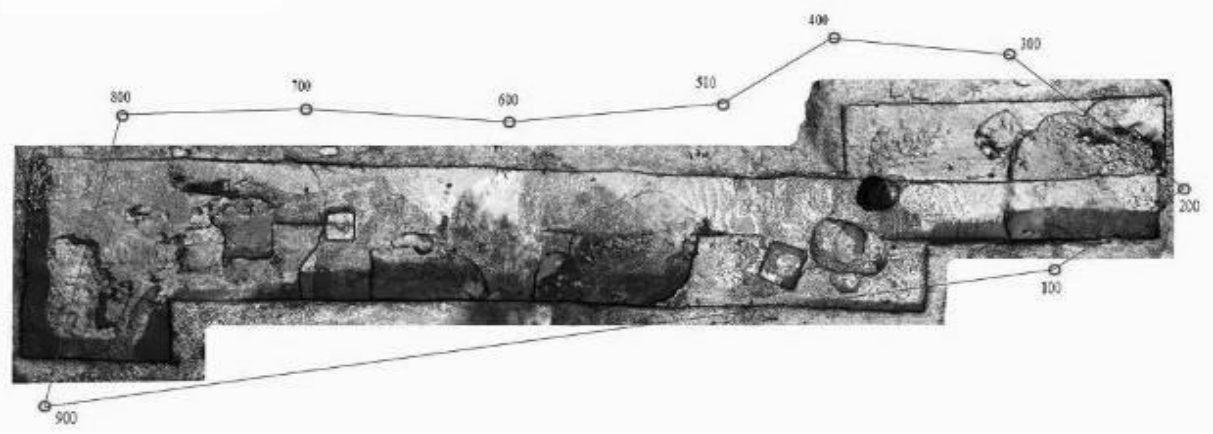

Fig. 3 The principal polygon of the local topographical network

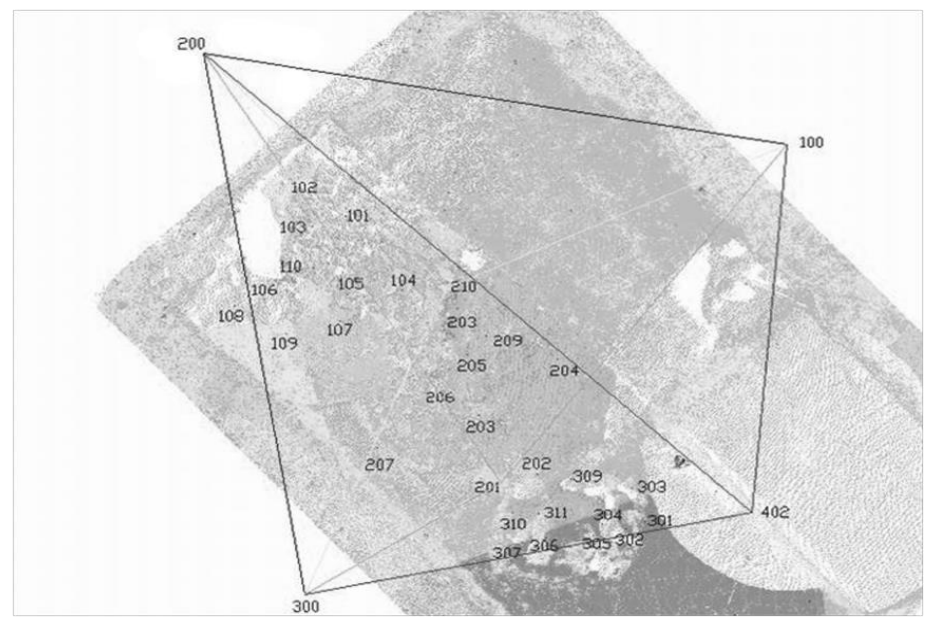

Fig.4 Detail of the local topographical network

The detail points have been individually noted with attention to all of the particulars and elements necessary to individuate them. Each field notebook was supplied with photographic monographs of the various elements in which the collimated natural points are visible. Nine monographs have been built comprehensively up in relation to the excavation zones chosen in consideration.

The archaeological area was in fact subdivided using an alphanumeric grid in the square areas (Fig. 5), and based on this subdivision it was possible to insert the finds in the table as reported in Table 1. 


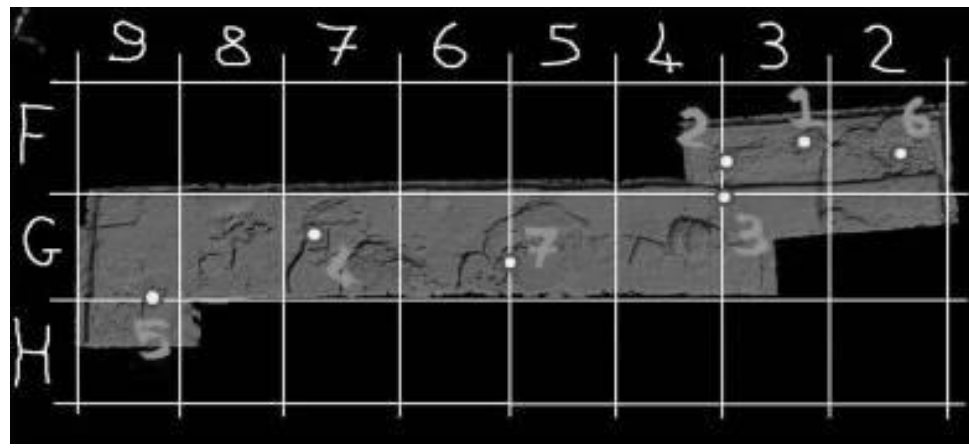

Fig. 5 Subdivision of the excavation area according to an alphanumeric grid

Table 1. Subdivision of the excavation area according to an alphanumeric grid.

\begin{tabular}{|c|c|c|c|c|c|c|c|c|}
\hline & 2 & 3 & 4 & 5 & 6 & 7 & 8 & 9 \\
\hline F & Find 6 & $\begin{array}{l}\text { Find 1 } \\
\text { Find 2 } \\
\text { Find 3 }\end{array}$ & Find 2 & - & - & - & - & - \\
\hline G & & Find 3 & Find 3 & Find 7 & Find 7 & Find 4 & & Find 5 \\
\hline H & & & & & & & & Find 5 \\
\hline
\end{tabular}

From the aforementioned table it can be seen how sometimes a given find can fall in various areas of the grid; for this reason it was decided to effectuate a further subdivision of the area, individuating six excavation zones each entirely containing one or more finds.

Lastly, for each find, various collimated natural points were identified from more than one vertex of the network, effectuating a triangulation in order to diminish the degree of uncertainty for each of the finds, corresponding, therefore, to a varying quantity of collimated points.

In particular, for each of the seven finds at least ten natural points were surveyed; in addition, there are two excavation zones that, presenting important details of the settlement, were also catalogued as additional finds.

\subsection{Laser scanner survey}

The problems relative to designing and executing a laser scanner survey are those relative to the choice of the measurement stations, with the aim of reducing the gray areas to a minimum and obtaining laser scan rich in detail; to such an end 14 scans were carried out (Costantino \& Angelini, 2012)

With the goal of obtaining a three-dimensional model of the excavation that could constitute a valid geometric support from a metrical point of view, on which all of the indepth analysis and integrations with the other information could be effectuated, a laser scanner survey was carried out using the Leica HDS300 TLS. It was necessary to effectuate an automatic registration (Fabris et al, 2009); the phases of registration of the individual scans was carried out using the proprietary software Cyclone and taking into consideration natural or artificial targets of predefined algorithms (Costantino \& Angelini, 2010; Costantino et al., 2010). 
The wealth of details allows an immediate analysis even of particular features, of discovered objects as well as of the shape and dimensions of the finds (Fig. 6)
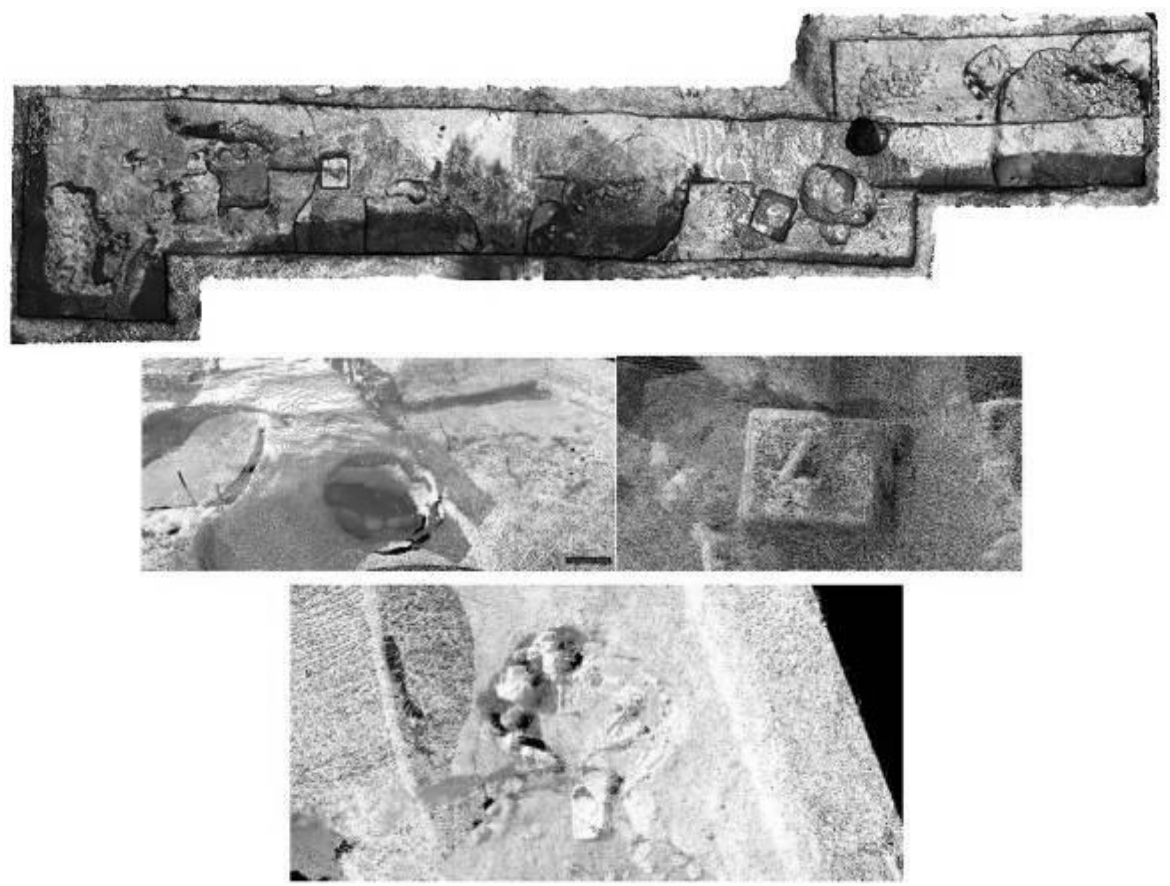

Fig. 6 3D TLS model with several particulars of the excavation area

\subsection{Photogrammetry survey}

A detailed acquisition of the finds discovered on the site were obtained with a calibrated Nikon D5000 camera with a fixed $35 \mathrm{~mm}$ lens, carrying out multiple shots of the same find from various angles and foreseeing the areas of superposition between them.

The software used for the 3D modelling of the particulars was PhotoScan, which carries out the photogrammetric elaboration of digital images and generates 3D spatial data with SFM algorithms (Chiabrando, Lingua \& Piras, 2013). The result is a dense point cloud put into association with the RGB information deriving from the digital images of the input, filtered for eventual noise.

\subsection{Integration of the tls and photogrammetric data}

The integration of the output data derived from different techniques of 3D modelling was carried out using standard formats that guaranteed the full compatibility and integration of the different point clouds - in particular, the data deriving from the laser scanner survey and from photogrammetry (Costantino \& Angelini, 2015).

However, it was necessary to implement preliminary procedures for the identification of the GCPs (Ground Control Points) in order to register the entire set of data.

The integration of the 3D laser model with the photogrammetric data, in fact, was conducted on the basis of the previously monographed points relating to the particulars of the excavation11 (Fig. 7) 


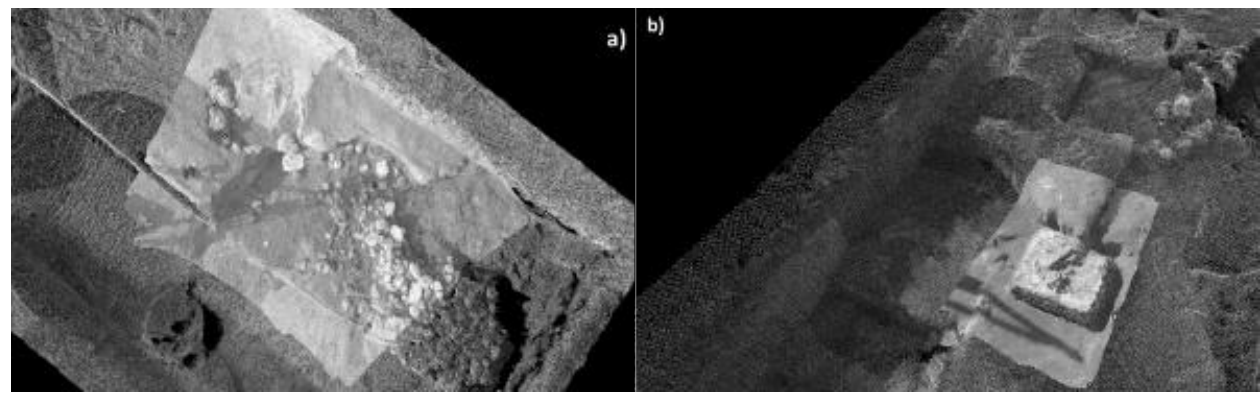

Fig. 7 Superposition of the point clouds of the particulars with the overall point cloud. In a) is depicted the particular of a ritual burial; in b) the discovery of a femur on a rectangular base

In order to obtain the 3D model of the surface of the particular detail, the comprehensive point cloud was subsequently elaborated in Geomagic (Fig. 8).

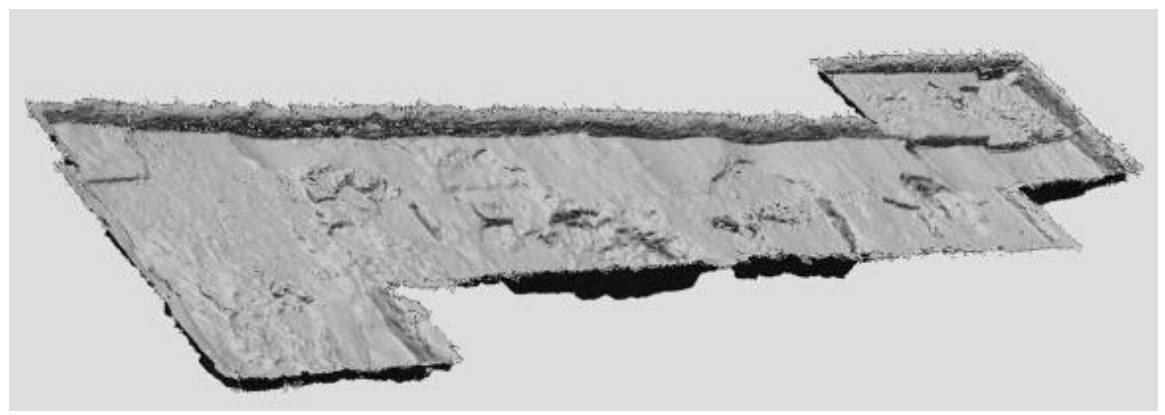

Fig.8 Mesh in Geomagic

\section{DATA FROM REMOTE SENSORS}

Methodologies of appropriate image processing were used to improve the identification of the tracings and archaeological anomalies by emphasising the spectral response of the satellite images. In particular, in order to furnish the geographical placement of the archaeological site in question, useful for the study of Neolithic civilisations in the area of Taranto, classic topographical and GNSS survey techniques were integrated with the data deriving from the analysis of a panchromatic Ikonos satellite image from 2000 .

This was first georeferenced in the UTM-WGS84 mapping system in the image-to-image mode using 29 GCPs individuated on the orthophoto from 2006, yielding an average RMS (Root Mean Square) equal to 0.6 pixels that can be considered an optimal result.

Subsequently, the excavation was classified in a supervised classification limited to the area surrounding the excavation, adopting the Maximum Likelihood algorithm that hypothesises a normal Gaussian distribution for each class. The result, with an accuracy of $89 \%$, is seen in figure 9. 


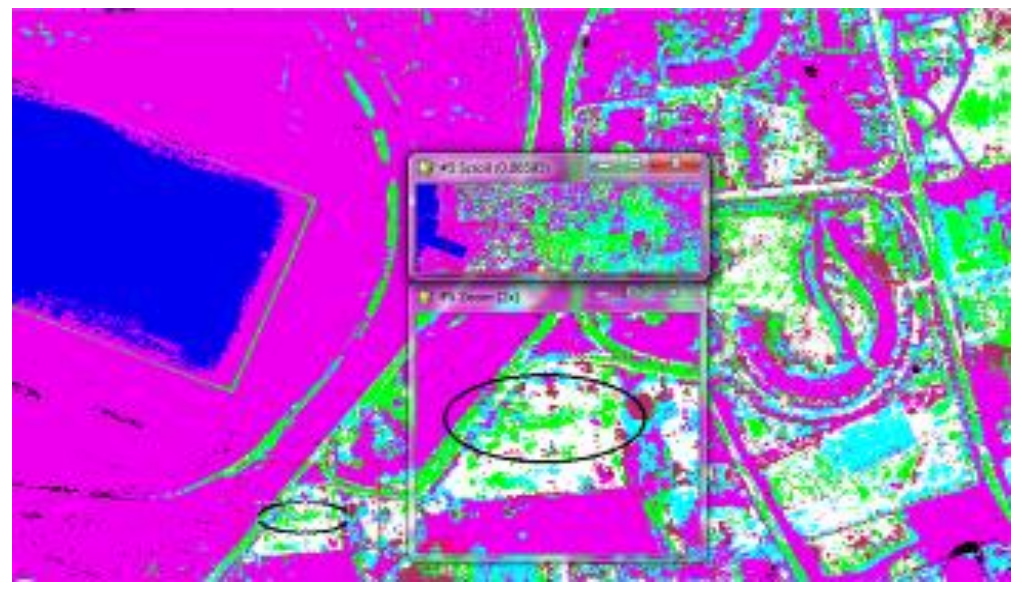

Fig. 9 Supervised classification of the Ikonos image

From the diachronic analysis of the extremely high-resolution optical satellite images, shown in the flowing figures, one can deduce that it is not possible to establish a priori which and how many indices of historical and cultural remains it would be possible to individuate with such information sources. It is in fact evident how the resolution plays a strategic role in the possibility of using such data for studying the evolution of this site under investigation. In effect, from the 2013 image (Fig. 10 a), most likely acquired from an aerial platform, and therefore of a better spatial resolution, one can recognise some of the forms of the structures that were already covered back up or in the process of being covered (Pulighe, Baiocchi \& Lupia, 2015).

The very high resolution of this image, connected to the azimuth of the sun at the moment of its acquisition, makes it possible in fact to point out even small differences in levels on the order of a few decimetres. For this reason, this approach would make it possible to individuate structures and remains that have yet to be noted. In the following images, however, one can observe that an inferior resolution obtained with methods of re-sampling diminishes the possibility of discrimination. From the image seen in figure $10 \mathrm{a}$, on the other hand, dating from 2004, it is possible to appreciate and recognise the site under investigation during the active campaign of excavation. In addition, the QuickBird satellite images already used have in fact undergone a treatment of "pan-sharpening," which is to say that the panchromatic images of higher resolution (around $0.61 \mathrm{~cm}$ ) were fused with the three separate bands of the primary colours (red, green and blue) that present a resolution some four degrees inferior. In practice, the higher-resolution black-and-white images were colourised.

The effects of such operations can be quite diverse and unpredictable: for example, one can observe the red "shadows" behind the automobiles in the 2009 photo (Fig. 10 c).

More generally, the processes of resampling tend to render the gray tones and various colours more uniform, making it more difficult to identify details of interest for research on the remains of historical and archaeological structures. A lot depends on the particular mode of acquisition, as one can observe in the image from 2002 (Fig. 10 d). The researchers wanted to use this last image in order to quickly evaluate the possibility of recognition using radar images: unfortunately, only an image with a resolution of 5 metres (Fig. 11) is available on the CosmoSkyMed archive, even though such a platform can, in some conditions, yield an image with a resolution of up to 1metre (the absolute survey capability in the field of radar satellites). 


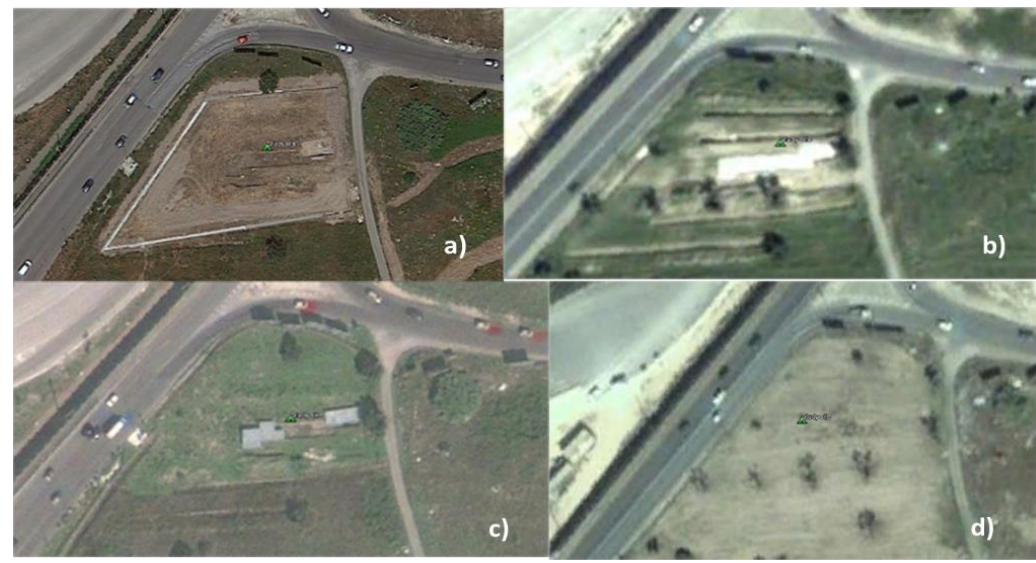

Fig. 10 a) 2013 aerial, b) 2004 Quickbird, c) 2009 Quickbird, d) 2002 Quickbird

Unfortunately, one can surmise even from a preliminary analysis that, at least at this resolution, it is not possible to individuate structures in relief or in the first few metres underground.

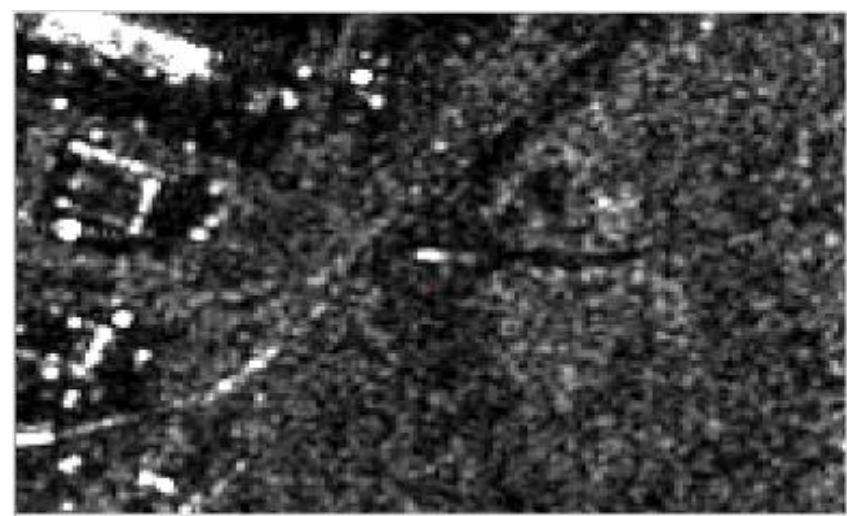

Fig. 11 CosmoSkyMed image from 2014

\section{CREATION OF DATA BASE}

In order to combine the needs for cataloguing, archiving and managing the heterogeneous mass of data relating to the excavation in question, a relational archaeological database was designed and structured for the subsequent management in a GIS context, choosing as the primary key the ID number assigned to each record entered into the system 12 (Costantino et al. 2016). So that the system would prove functional and could represent an efficient instrument for the production of knowledge, it was considered necessary to focus attention on several aspects:

- The creation of a structure easy to integrate with new types of information deriving from the changing dynamics of research in individual contexts;

- $\quad$ The possibility of updating the inserted data with the most ease and least time spent;

- The creation of an intuitive user interface by means of simple menus or windows or simple interrogation or informational shortcuts. 
From the primary window it is possible to access all of the archives and all of the information regarding the archaeological mission in question, organised in such a way as to be able to quickly and easily access all the archived data: maps, photographs, literary and historical documentation, personal and contact information for all the members of the mission, as well as for the principal partners and financers of the mission, etc. (Fig. 12).
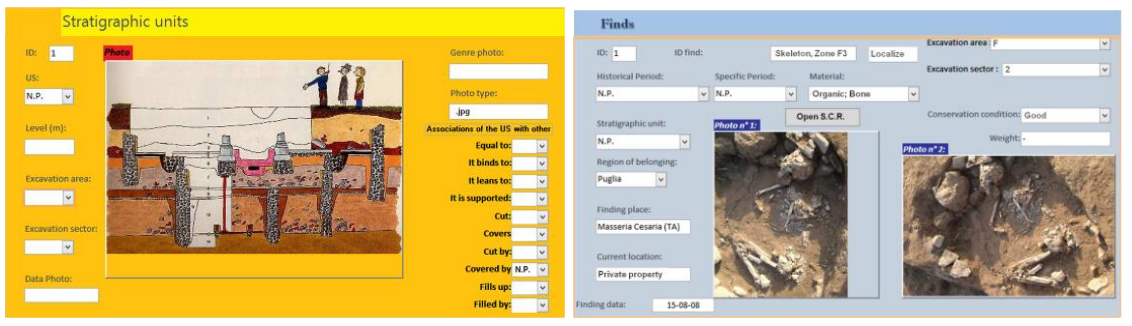

Fig. 12 Window for the US archive

The complex of the database developed cannot be described here fully and it will be illustrated in future works.

\section{CONCLUSIONS}

The various problems addressed in the phases of elaboration derive either from the need to furnish documentation at once measurable and easily interpretable on the part of the final users, who do not always have experience in managing three-dimensional data, or from the need to integrate data acquired with diverse survey techniques. With regard to the terrestrial laser scanner applied to the archaeological sector, the phases of data processing were addressed, analyzed, and applied to data acquired in 2007. Given the lack of homogeneity of the various data and the high level of articulation in the multiple operational phases, which result in long elaboration times, the ability of the operator managing these to operate with the diverse software programs for managing and modeling the irregular surfaces is of fundamental importance. It proved possible to combine the highly accurate geometry of the laser data integrated with the photogrammetric data together with the RGB information, obtaining a textured 3D model that is at once metrically valid and descriptive. Both the terrestrial laser scanner technique and the photogrammetric technique have allowed for a visualization of the site that is at once comprehensive and detailed. For each phase of the survey, elaboration and excavation activity, the support furnished by the use of the integrated database system and the GIS proved consequential, as in the context this allowed for easier management and cataloguing of the excavation and survey operations, and also constituted the subsequent integrated archive for consulting and managing the archaeological, topographical, historical and documentary data.

\section{R E F E R E N C E S}

Baiocchi, V., Dominici, D. \& Mormile, M. (2013) UAV application in post - Seismic environment. International Archives of the Photogrammetry, Remote Sensing and Spatial Information Sciences - ISPRS Archives, 40 (1/W2), 21-25.

Baiocchi, V., Dominici, D., Giannone, F. \& Zucconi, M. (2012) Rapid building damage assessment using EROS B data: The case study of L'Aquila earthquake. Italian Journal of Remote Sensing / Rivista Italiana di Telerilevamento, 44 (1), 153-165, DOI: 10.5721/ItJRS201244112. 
Brigante, R. \& Radicioni, F. (2014) Metric-historical studies for the monitoring of the walls of Amelia. Citta e Storia, 9 (1), 111-129.

Chiabrando, F., Lingua, A. \& Piras, M. (2013) Direct photogrammetry using UAV: Tests and first results International Archives of the Photogrammetry. Remote Sensing and Spatial Information Sciences - ISPRS Archives, 40 (1/W2), 81-86.

Corrado, A. \& Ingravallo, E. (1988) L'insediamento di masseria Le Fiatte (Manduria) nel popolamento neolitico del Nord-Ovest del Salento. Studi di Antichità, 5, 5-78.

Costantino, D. \& Angelini, M. G. (2012) Process Modeling and Photogrammetric Production for Structural Investigations Concerning to the Collapse of Palazzo Edilizia in Salerno (Italy). Lecture notes in Computer Science, 7616, 440-448, DOI 10.1007/978-3-642-34234-9_45.

Costantino, D., \& Angelini, M. G. (2010) Realization of a Cartographic GIS for the Filing and Management of the Archaeological Excavations in the Nelson's Island. Lecture notes in Computer Science, 6436, 513-527, DOI 10.1007/978-3-642-16873-4_42.

Costantino, D., \& Angelini, M.G. (2015) Integrated survey for quarries monitoring. Geographia Technica, 10 (2), 20-28.

Costantino, D., Angelini, M. G., \& Caprino G. (2010) Laser scanner survey of an archaeological site - Scala di Furno (Lecce, Italy). ISPRS Commission V, Mid - Term Symposium "Close range image measurements techniques, XXXVIII, Part 5, 178-183.

Costantino, D., Angelini, M.G., Claveri, M., \& Alfio, V.S. (2016) Document GIS and DBMS implementation for the development of rural areas of the "one hundred masserie" of Crispiano. Geographia Technica, 11 (1), 23-32.

Costantino, D., Guarnieri A., Vettore A., \& Camarda M. (2011) Automatic Registration of Large Range Datasets with Spin-Images. Journal of Cultural Heritage, 12 (4), 476-484.

Cremonesi, G. (1979) Il neolitico e l'inizio dell'Età dei metalli nel Salento. Dal Paleolitico al Tardo Antico, Milano, 99-110.

Coppola, D. (1988) La distribuzione degli insediamenti e delle grotte nel Brindisino e nel Tarantino. Contributo allo studio delle origini e della diffusione della civiltà neolitica. Lingua e storia in Puglia, 11, 73-116.

Del Monaco, O. (1993) Archeologia, civiltà e culture nell'area Ionico-Tarantina, Fasano, 6-159.

Dominici, D., Rosciano, E., Alicandro, M., Elaiopoulos, M., Trigliozzi, S. \& Massimi, V. (2013) Cultural heritage documentation using geomatic techniques: Case study: San Basilio's monastery, L'Aquila. Proceedings of the DigitalHeritage International Congress. DOI: 10.1109/DigitalHeritage.2013.6743735.

Fabris, M., Achilli V., Artese G., Boatto G., Bragagnolo D., Cancheri G., Meneghello R., Menin A. \& Trecroci A. (2009) High resolution data from laser scanning and digital photogrammetry terrestrial methodologies. Test site: an architectural surface. International Archives of the Photogrammetry, Remote Sensing and Spatial Information Sciences, 38, (3/W8), 43-48.

Fedele, B. (1972) Insediamenti neolitici a Sud-Est di Taranto. Archivio Storico Pugliese, 25, $127-$ 190.

Gambassini, P. (1999) Preistoria. L'uomo preistorico. In: Guide Geologiche Regionali, Puglia e Monte Vulture, ed. Società Geologica Italiana. Ed. BE-MA;

Guaitoli, M. (2000) I Sistemi Informativi Territoriali in rapporto al patrimonio archeologico. In: Problemi della "Chora" coloniale dall'Occidente al Mar Nero: atti del quarantesimo Convegno di Studi sulla Magna Grecia, Taranto, 29 Septembre - 3 October, 385-402.

Pulighe, G., Baiocchi, V., \& Lupia, F. (2015) Horizontal accuracy assessment of very high resolution Google Earth images in the city of Rome, Italy. International Journal of Digital Earth, 9 (4), (article in Press). DOI: 10.1080/17538947.2015.1031716. 